\title{
Optimal Sizing of the Stand-Alone Photovoltaic System for a Solar-Powered Translational Sprinkler Irrigation Machine considering the Loss of Power Supply Probability
}

\author{
Kenan Liu, Bugong Sun ${ }^{(D)}$, Xiaoyang Gao, Yang Zhang, Wei Sun, Quan Feng, \\ and Wanxia Yang \\ School of Mechanical and Electrical Engineering, Gansu Agricultural University, Lanzhou 730070, China \\ Correspondence should be addressed to Bugong Sun; sunbg@gsau.edu.cn
}

Received 19 October 2021; Accepted 23 December 2021; Published 19 January 2022

Academic Editor: Licheng Wang

Copyright $\odot 2022$ Kenan Liu et al. This is an open access article distributed under the Creative Commons Attribution License, which permits unrestricted use, distribution, and reproduction in any medium, provided the original work is properly cited.

\begin{abstract}
The translational sprinkler irrigation machine is widely used because of its high degree of automation, less manual investment, and convenient movement. However, when using the sprinkler irrigation machine, the power supply is difficult to be guaranteed in some remote power shortage areas. Solar energy has become one of the best choices for the power source of sprinkler irrigation machines. An important issue is the optimal sizing of the stand-alone photovoltaic system for a solar-powered translational sprinkler irrigation machine. This work conducts the optimal sizing of the stand-alone photovoltaic system for a solar-powered translational sprinkler irrigation machine considering the loss of power supply probability. Firstly, the self-developed translational sprinkler irrigation machine is introduced. The load power, which includes the driving power of the translational sprinkler irrigation machine, water intake pressure driving power, and the loss power of the controller and sensors, is considered in the calculation process. Subsequently, the photovoltaic generator model and the battery storage model are established. Then, the stand-alone photovoltaic system is optimized considering the loss of power supply probability (LPSP) and the life cycle cost (LCC). After the solar irradiance and ambient temperature of a typical sunny day in the test area are given, the optimal combination of the PV module and battery is obtained. The optimal sizing result is verified using the PV power, state of charge (SOC), and load power. The presented optimal sizing method is also compared with an existing method. Besides, the operation test of the sprinkler irrigation machine is also carried out to verify the optimal sizing result. The optimal sizing result is proved to be effective and applicable.
\end{abstract}

\section{Introduction}

The development of irrigation machinery is one of the guarantee factors to improve crop yield. How to save water and energy for irrigation has become an inevitable trend in modern agricultural development. The translational sprinkler irrigation machine is widely used because of its high degree of automation, less manual investment, and convenient movement. However, the power supply is difficult to guarantee when using the sprinkler irrigation machine in some remote power shortage areas. These power shortage areas cannot be irrigated in time. Solar energy is clean and environment-friendly energy. With the maturity of photovoltaic technology, solar energy has become one of the best choices for sprinkler irrigation machine power.

The solar-powered translational sprinkler irrigation machine transforms the traditional farmland irrigation mode into mobile sprinkler irrigation with high uniformity of irrigation. An important issue is the optimal sizing of the stand-alone photovoltaic system for a solar-powered translational sprinkler irrigation machine. At present, there are fewer studies on the matching of power demand and solar photovoltaic power during the operation of solarpowered sprinkler irrigation machines. The sprinkler irrigation machinery powered by solar is not mature, which limits its popularization and application in agriculture. At 
present, the research on solar-powered machinery mostly focuses on the research of solar vehicles, such as [1-3].

Many efforts have been made regarding the optimal sizing of the stand-alone photovoltaic system. Benmouiza et al. [4] presented an optimization method for designing the standalone photovoltaic system. This work mainly compares the proposed method with the existing methods. However, the specific application of the method is not illustrated. Aziz et al. [5] optimized the stand-alone photovoltaic system by minimizing the loss of power supply probability. In this study, only the loss of power supply probability (LPSP) was considered without considering the stand-alone photovoltaic system's life cycle cost (LCC). Fezai et al. [6] proposed a methodology to study the load profile impact on the stand-alone photovoltaic system reliability and storage component. Senol et al. [7] studied the technical and economic feasibility of photovoltaic pumping of water in Turkey. This study only considered the life cycle cost (LCC), ignoring the loss of power supply probability (LPSP). Sallem et al. $[8,9]$ presented a new management approach that makes the decision on the optimum connection times of the elements of a photovoltaic water pumping installation. However, this paper does not optimize the configuration from the aspects of LCC and LPSP.

At present, most of the research on the optimal sizing of the stand-alone photovoltaic system focuses on the power supply-demand for residential households or rural areas. Abbes et al. [10] proposed a new methodology with the aim to design an autonomous hybrid PV-wind-battery system. The electric demand of a residential house is taken as an example to verify the proposed method. Bataineh et al. [11] designed a stand-alone photovoltaic (PV) system to provide the required electricity for a single residential household in a rural area in Jordan. Koutroulis et al. [12] presented a methodology for optimal sizing of stand-alone photovoltaic/wind generator systems. The proposed method has been applied to design a power generation system that supplies a residential household. Okoye et al. [13] studied the optimal sizing of standalone photovoltaic systems in residential buildings. As mentioned above, there are a few studies on the walking power demand and photovoltaic power matching design for the solar-powered sprinkler irrigation machine. Therefore, this work aims to optimize the stand-alone photovoltaic system for a solar-powered translational sprinkler irrigation machine considering the loss of power supply probability.

The rest of this paper is organized as follows. In Section 2 , the stand-alone photovoltaic system configuration model is introduced. In Section 3, the stand-alone photovoltaic system is optimized considering the loss of power supply probability. In Section 4, the optimal combination of PV module and battery are obtained, and relevant discussions are carried out. Conclusions are drawn in Section 5.

\section{Stand-Alone Photovoltaic System Configuration Model}

2.1. The Self-Developed Translational Sprinkler Irrigation Machine. This study uses the self-developed translational sprinkler irrigation machine as the research objective, and its structural diagram is shown in Figure 1.
Figure 1 mainly introduces the main structure of the selfdeveloped translational sprinkler irrigation machine. The self-developed translational sprinkler irrigation machine comprises the solar photovoltaic power supply, mechanical structure, and control system parts. As shown in Figure 1, the self-developed sprinkler irrigation machine mainly includes the solar photovoltaic module, battery, main water pipe, water pump, steering motor, high-clearance chassis, control cabinet, walking motor reducer, nozzle, and so on. The detailed information of the developed translational sprinkler irrigation machine is described in [14].

\subsection{Driving Power of the Translational Sprinkler Irrigation} Machine. The driving power of the translational sprinkler irrigation machine $P_{\mathrm{d}}$ can be given by

$$
P_{d}=\frac{m g f v_{\max }}{\eta} \alpha
$$

where $m$ is the maximum mass of the translational sprinkler irrigation machine after filling water into the water tank, $g$ is the acceleration of gravity, $f$ is the rolling resistance coefficient, $v_{\max }$ is the maximum travelling speed of the translational sprinkler irrigation machine, $a$ is the safety factor, and $\eta$ is the mechanical transmission efficiency. For this study, the parameters $m, g, f, v_{\max }, \alpha$, and $\eta$ are chosen as $3500 \mathrm{~kg}, 9.8 \mathrm{~m} / \mathrm{s}^{2}, 0.3,0.028 \mathrm{~m} / \mathrm{s}, 1.2$, and 0.8 , respectively.

2.3. Water Intake Pressure Driving Power. The translational sprinkler irrigation machine is mainly used for crop irrigation, pesticide spraying, and fertilization. According to the inflow pressure and flow requirements of the unit design, the water intake pressure driving power required by sprinkler irrigation unit can be expressed as follows:

$$
P_{p}=\frac{\rho g Q H}{3600 \eta_{P}} \alpha,
$$

where $\rho$ is the water density, $Q$ is the flow of the pumping unit, $H$ is the water-lift of the self-priming pump of the translational sprinkler irrigation machine, $\alpha$ is the safety factor, and $\eta_{\mathrm{p}}$ is the efficiency of the pump pressurization system, which includes water pump efficiency and DC brushless motor efficiency. For this study, the parameters $\rho$, $Q, H, \alpha$, and $\eta_{\mathrm{p}}$ are chosen as $1000 \mathrm{~kg} / \mathrm{m}^{3}, 12 \mathrm{~m}^{3} / \mathrm{h}, 10 \mathrm{~m}, 1.2$, and 0.54 , respectively.

2.4. The Loss Power of the Controller and Sensors. The loss power of the controller and sensors of the unit $P_{\mathrm{c}}$ is also taken into consideration. In this study, $P_{\mathrm{c}}$ is chosen as $100 \mathrm{~W}$.

The total load power $P_{1}$ can be represented as follows:

$$
P_{l}=P_{d}+P_{p}+P_{c} \text {. }
$$

2.5. Photovoltaic Generator Model. The output electric power of the photovoltaic generator can be written as follows: 


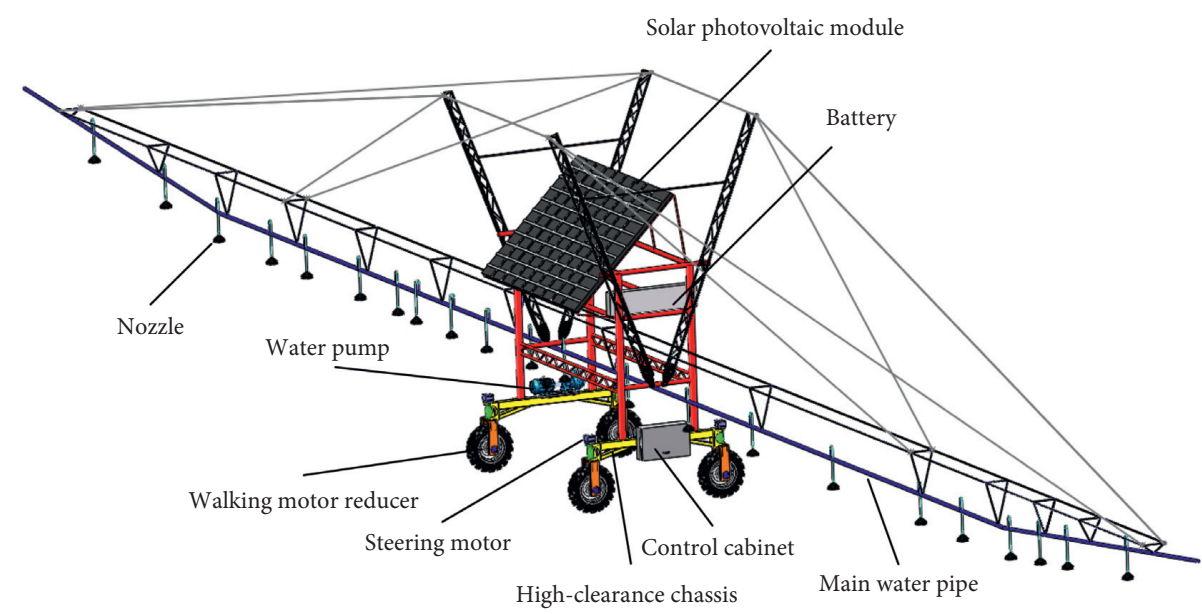

Figure 1: Structural diagrams of the developed translational sprinkler irrigation machine.

$$
P_{\mathrm{pv}}=N_{\mathrm{pv}} \times \eta_{\mathrm{pv}} \times A_{\mathrm{pv}} \times I_{r}
$$

where $N_{\mathrm{pv}}$ is the number of PV modules, $\eta_{\mathrm{pv}}$ is the power conversion efficiency, $A_{\mathrm{pv}}$ is the surface area of PV panels of a single module, and $I_{r}$ is the solar radiation. The power conversion efficiency $\eta_{\mathrm{pv}}$ can be expressed by the following equation:

$$
\eta_{\mathrm{pv}}=\eta_{r} \times \eta_{\mathrm{pc}} \times\left[1-\beta_{\text {getc }} \times\left(T_{c}-\mathrm{NOCT}\right)\right],
$$

where $\eta_{r}$ is the reference module efficiency, $\eta_{\mathrm{pc}}$ is the power condition efficiency, $\beta_{\text {getc }}$ is the generator efficiency temperature coefficient, $T_{c}$ is the cell temperature, and NOCT is the normal operating cell temperature when cells operate under standard operating conditions. $T_{\mathrm{c}}$ can be estimated as follows:

$$
T_{C}=30+0.0175 \times\left(I_{r}-300\right)+1.14 \times\left(T_{a}-25\right),
$$

where $T_{a}$ is ambient temperature $\left({ }^{\circ} \mathrm{C}\right)$.

2.6. Battery Storage Model. In this study, the lead-acid battery is used in the stand-alone photovoltaic system due to low cost, high reliability, convenient maintenance, and so on. The state of charge (SOC) is determined by using the difference between the generated PV power and the load power. When the generated PV power is greater than the load power, the energy produced by the PV system can satisfy the demand of the load. Meanwhile, the extra energy produced by the PV system will be stored in the battery, which corresponds to the charging process. On the contrary, when the generated PV power is less than the load power, the demand of load cannot be satisfied. The stored energy will be released to guarantee the demand of load, which corresponds to the discharging process.

The state of charge (SOC) is used to reflect the battery's remaining power in real-time. It can be defined by using the ratio of the battery's remaining capacity to the rated capacity at a certain time.

When charging, the SOC of the battery at the time $t$ is expressed as follows:

$$
\operatorname{SOC}(t)=\operatorname{SOC}(t-\Delta t)+\frac{\Delta E_{\text {store }} \eta_{\text {in }}}{N_{b} E_{\text {rate }}}
$$

When discharging, the SOC of the battery at the time $t$ is expressed as follows:

$$
\operatorname{SOC}(t)=\operatorname{SOC}(t-\Delta t)-\frac{\Delta E_{\text {store }}}{\eta_{\text {out }} N_{b} E_{\text {rate }}},
$$

where $\operatorname{SOC}(t)$ and $\operatorname{SOC}(t-\Delta t)$ are the states of charge of the battery at the time $t$ and $t-\Delta t$, respectively, $\Delta E_{\text {store }}$ is the amount of energy charged or discharged by the battery during period $\Delta t, \eta_{\text {in }}$ and $\eta_{\text {out }}$ are the charging and discharging efficiency of the battery system, respectively, $N_{b}$ is the number of batteries, and $\Delta E_{\text {store }}$ is the rated capacity of the battery.

When the PV power is greater than the load power, the extra PV power will be stored in the battery. The theoretical charging capacity of the battery within time $t$ and $t+\Delta t$ is expressed as follows:

$$
\Delta E_{\text {store }}=\left[P_{\mathrm{pv}}(t)-\frac{P_{l}(t)}{\eta_{\text {inv }}}\right] \Delta t .
$$

When the PV power is less than the load power, and the sum of the PV power and the battery discharge power is greater than the load power, the battery needs to release power to meet the load demand. The theoretical discharging capacity of the battery within time $t$ and $t+\Delta t$ is expressed as follows:

$$
\Delta E_{\text {store }}=\left[\frac{P_{l}(t)}{\eta_{\text {inv }}}-P_{p v}(t)\right] \Delta t .
$$

The state of charge of the battery should not exceed the upper limit $S O C_{\max }$ and not be lower than the lower limit $S O C_{\text {min }}$, which is expressed as follows:

$$
\mathrm{SOC}_{\min } \leq \mathrm{SOC}(t) \leq \mathrm{SOC}_{\max } .
$$

When $\operatorname{SOC}(t+\Delta t)<S O C_{\min }$, the actual discharge capacity of the battery during time $t$ and $t+\Delta t$ can be expressed as follows: 


$$
\Delta E_{\text {discharge }}=N_{b} E_{\text {rate }}\left(S O C(t)-S O C_{\min }\right) .
$$

When the sum of the PV power and the battery discharge power is less than the load power, the loss of power supply (LPS) will happen. The capacity of the LPS, i.e., $Q_{L P S}(t)$, can be calculated as follows:

$$
\mathrm{Q}_{\mathrm{LPS}}(t)=\left[P_{l}(t)-\left(P_{\mathrm{pv}}(t)+P_{\text {discharge }}\right) \times \eta_{\mathrm{inv}}\right] \Delta t,
$$

where $P_{\text {discharge }}$ is the discharge power of the battery.

When SOC $(t+\Delta t)>$ SOC $_{\text {max }}$, the actual charge capacity of the battery during time $t$ and $t+\Delta t$ can be expressed as follows:

$$
\Delta E_{\text {charge }}=N_{b} E_{\text {rate }}\left(\mathrm{SOC}_{\max }-\mathrm{SOC}(t)\right) .
$$

In this study, it is assumed that the battery is full charged. That is, the initial value of SOC is chosen as $100 \%$.

\section{Optimal Sizing of the Stand-Alone Photovoltaic System}

3.1. Objective Function. Optimal sizing of the stand-alone photovoltaic system aims to minimize the life cycle cost (LCC) of the system on the premise of meeting the load power demand and power supply reliability. In this study, the LCC includes equipment cost $C_{\mathrm{E}}$, the present worth of equipment replacement cost after $n$ years $C_{\mathrm{EnPW}}$, installation cost $C_{\text {Inst }}$, and the present worth of maintenance cost $C_{\mathrm{MPW}}$. Therefore, the objective function of the LCC for the standalone photovoltaic system can be expressed as

$$
\min \mathrm{LCC}=C_{E}+C_{\mathrm{EnPW}}+C_{\text {Inst }}+C_{\mathrm{MPW}} \text {, }
$$

where the equipment cost $C_{\mathrm{E}}$ mainly contains the cost of the $\mathrm{PV}$ modules, batteries, and controller, which are represented by $C_{\mathrm{PV}}, C_{\mathrm{B}}$, and $C_{\mathrm{c}}$, respectively. Accordingly, the equipment cost $C_{\mathrm{E}}$ can be represented as

$$
C_{E}=C_{\mathrm{PV}}+C_{B}+C_{c} .
$$

In our study, the cost of each photovoltaic panel is 1000 $\mathrm{RMB}$, the cost of each battery is $600 \mathrm{RMB}$, and the cost of the controller is $1600 \mathrm{RMB}$. Then, equation (16) can be rewritten as

$$
C_{E}=1000 \times N_{\mathrm{pv}}+600 \times N_{b}+1600 .
$$

In this work, the operating life of the photovoltaic system $\mathrm{N}$ is set as 20 years, namely, $N=20$. The life of the battery is assumed to be five years, and the life of the PV modules and controller is assumed to be 20 years. Therefore, only the present worth of the battery replacement cost after $n$ years i.e., $C_{\mathrm{BnPW}}$, should be considered in the operating life of the photovoltaic system, i.e., $C_{\mathrm{EnPW}}=C_{\mathrm{BnPW}}$. The present worth of the battery replacement cost after $n$ years can be calculated as follows:

$$
C_{\mathrm{BnPW}}=C_{B}\left(\frac{1+i}{1+d}\right)^{n}
$$

where $i$ and $d$ represent the inflation rate and discount rate, respectively. During calculation, the inflation rate $i$ and discount rate $d$ are taken as $3 \%$ and 5\%, respectively. Since the operating life of the photovoltaic system is 20 years and the life of the battery is assumed to be five years, $n$ is chosen as 5,10 , and 15 . Substituting the value of the parameters into equation (18), the following equation can be obtained:

$$
C_{\mathrm{BnPW}}=600 \times N_{b} \times\left[\left(\frac{1+3 \%}{1+5 \%}\right)^{5}+\left(\frac{1+3 \%}{1+5 \%}\right)^{10}+\left(\frac{1+3 \%}{1+5 \%}\right)^{15}\right]=1489.7 \times N_{b}
$$

The installation cost is assumed $10 \%$ of the PV modules cost, which can be expressed as follows:

$$
C_{\text {Inst }}=10 \% \times 1000 \times N_{\mathrm{pv}}=100 \times N_{\mathrm{pv}} .
$$

The present worth of maintenance cost $\mathrm{C}_{\mathrm{MPW}}$ can be acquired as follows:

$$
C_{\mathrm{MPW}}=C_{\mathrm{MPY}} \times\left(\frac{1+i}{1+d}\right) \times \frac{1-((1+i) /(1+d))^{N}}{1-(1+i) /(1+d)},
$$

where $C_{\mathrm{MPY}}$ is the maintenance cost per year, which is assumed $2 \%$ of the PV modules cost. Substituting the parameter value into equation (21), we can get

$$
C_{\mathrm{MPY}}=2 \% \times 1000 \times N_{\mathrm{pv}} \times\left(\frac{1+3 \%}{1+5 \%}\right) \times \frac{1-((1+3 \%) /(1+5 \%))^{20}}{1-(1+3 \%) /(1+5 \%)}=328.87 \times N_{\mathrm{pv}}
$$

Combining equations (17), (19), (20), and (22), the life cycle cost of the system LCC can be expressed as follows:

$$
L C C=1428.87 \times N_{\mathrm{pv}}+2089.7 \times N_{\mathrm{b}}+1600 .
$$

\subsection{Optimization Constraints}

3.2.1. Power Supply Reliability Constraint. The loss of power supply probability (LPSP) represents the probability that the photovoltaic system cannot meet the load power demand 
within the evaluation period $T$. The LPSP can be expressed as the ratio of load power shortage to total load demand in the time period. In this study, LPSP is taken as the power supply reliability index, which can be calculated as follows:

$$
\operatorname{LPSP}(t)=\frac{\sum_{t=t_{0}}^{t_{0}+k \Delta t}\left[P_{l}(t)-\left(P_{\mathrm{PV}}(t)+P_{\text {discharge }}(t)\right) \times \eta_{\text {inv }}\right] \Delta t}{\sum_{t=t_{0}}^{t_{0}+k \Delta t} P_{l}(t) \Delta t},
$$

where $k$ is the time series for evaluation. When LPSP $=0$, it indicates that the power supply of the system can be satisfied; when $\operatorname{LPSP}=1$, it indicates that the power supply of the system cannot be satisfied. Therefore, the constraint corresponding to the power supply reliability is expressed as

$$
g 1=\max (\operatorname{LPSP}(t))-\operatorname{LPSP}_{\max } \leq 0 .
$$

3.2.2. Battery Power Constraint. To prevent the service life of the battery from being affected by over charge or over discharge, the state of charge of the battery should meet the following constraint:

$$
\mathrm{SOC}_{\min } \leq \mathrm{SOC}(t) \leq \mathrm{SOC}_{\max } .
$$

In this work, the $\mathrm{SOC}_{\min }$ and $\mathrm{SOC}_{\max }$ are chosen as the $20 \%$ and $80 \%$, respectively.

To better demonstrate the optimization process and algorithm logic, the corresponding flow chart is presented, as shown in Figure 2.

\section{Results and Discussion}

4.1. Determination of the Optimal Combination of PV Module and Battery. Solar irradiance and ambient temperature are important input parameters of the optimization model. The AV6592 type portable tester (voltage accuracy $0.01 \mathrm{~V}$, current accuracy $0.001 \mathrm{~A}$, and power range $0.1 \sim 500 \mathrm{~W}$ ) was used to monitor the solar irradiance and ambient temperature in the test area (east longitude $108.07^{\circ}$, northern latitude $34.28^{\circ}$, and height above sea level $521 \mathrm{~m}$ ). The single-crystal photovoltaic panel type CS5M32-260 and the valve regulated fully sealed lead-acid battery typed $190 \mathrm{H} 52$ (capacity $200 \mathrm{~A} \cdot \mathrm{h}$, rated voltage $12 \mathrm{~V}$ ) are used in this work. The monitoring time is from April 29 to May 29, 2018, a total of 31 days. During the days of monitoring, the translational sprinkler irrigation machine works 8 hours a day, from 9 a.m. to 5 p.m. The solar irradiance and ambient temperature within 248 hours are shown in Figure 3.

As shown in Figure 3, the solar irradiance and ambient temperature within the total monitoring time show randomness and irregular variation due to the complex climatic conditions. In this study, the developed translational sprinkler irrigation machine has a lightweight and small- and mediumsize structure powered by the stand-alone photovoltaic system. Suppose the sprinkler irrigation machine is guaranteed to operate continuously under non-sunny weather conditions. In that case, more photovoltaic modules and batteries will be required, which may exceed the bearing range of the design structure. Therefore, the developed translational sprinkler irrigation machine has the best applicability under sunny weather conditions. In addition, sprinkler irrigation is more necessary in sunny weather conditions. The solar irradiance and ambient temperature of a typical sunny day in the test area are shown in Figure 4.

In Figure 4(b), the red curve is the fitting of the ambient temperature for a typical sunny day. It can be seen from Figure 4 that under the typical sunny weather condition in the test area the solar irradiance and ambient temperature reach the maximum between 13:00 and 14:00. The other main input parameters are listed in Table 1.

As mentioned above, when the photovoltaic (PV) system cannot meet the load power demand, the loss of power supply will happen. The loss of power supply probability (LPSP) varies with the combinations of PV module and battery. Considering the small- and medium-size structure of the developed translational sprinkler irrigation machine, the number of photovoltaic modules and batteries should not be too large. In this study, the number of photovoltaic modules ranges from 1 to 25 , and the number of batteries also ranges from 1 to 25 . That is, $1 \leq N_{\mathrm{pv}} \leq 25$, and $1 \leq N_{\mathrm{b}} \leq 25$. The relationship among the number of photovoltaic modules, the number of batteries, and the LPSPs is shown in Figure 5.

In Figure 5, the curves are the boundaries between the desirable and undesirable LPSPs. It can be seen from Figure 5 that the larger the LPSP, the more combinations of PV module and battery can be selected. The purpose of optimal sizing is to minimize the life cycle cost (LCC) on the premise that LPSP meets the requirements. The life cycle cost (LCC) comparison for different combinations of photovoltaic module and battery is shown in Table 2 .

As shown in Table 2, with the increase of the number of PV modules and batteries, the LPSPs decrease, but the corresponding LCC increases. In addition, when $N_{\mathrm{pv}}=16$ and $N_{\mathrm{b}}=2$, it can also make $\mathrm{LPSP}=0$. The relationship between LPSP and LCC is shown in Figure 6.

As can be seen from Figure 6, we mainly divide the parameter plane into three regions, i.e., regions $A, B$, and C. The LPSP corresponding to region $\mathrm{A}$ is small, but the smaller LPSP is based on the sacrifice of LCC. As for region $\mathrm{B}$, the corresponding LPSP is greater than that in region $\mathrm{A}$, while the corresponding LCC is not reduced much. The LPSP corresponding to region $\mathrm{C}$ is larger than that in regions $\mathrm{A}$ and $\mathrm{B}$, but the corresponding LCC is smaller than that in regions $\mathrm{A}$ and $\mathrm{B}$. In this study, to ensure the continuous operation of the sprinkler irrigation machine, the maximum LPSP is set to 0; that is, there is no power loss during the operation of the sprinkler irrigation machine under typical sunny weather conditions.

After comparative analysis, the combination of $\mathrm{PV}$ module and battery with $N_{\mathrm{pv}}=16$ and $N_{\mathrm{b}}=2$ is proved the optimal one, the LCC of which is minimum and whose LPSP also meets the requirements $(\mathrm{LPSP}=0)$.

4.2. Comparison with the Existing Method. In this section, by combining the data listed in Table 2, the optimization sizing method presented in this manuscript is compared with the 


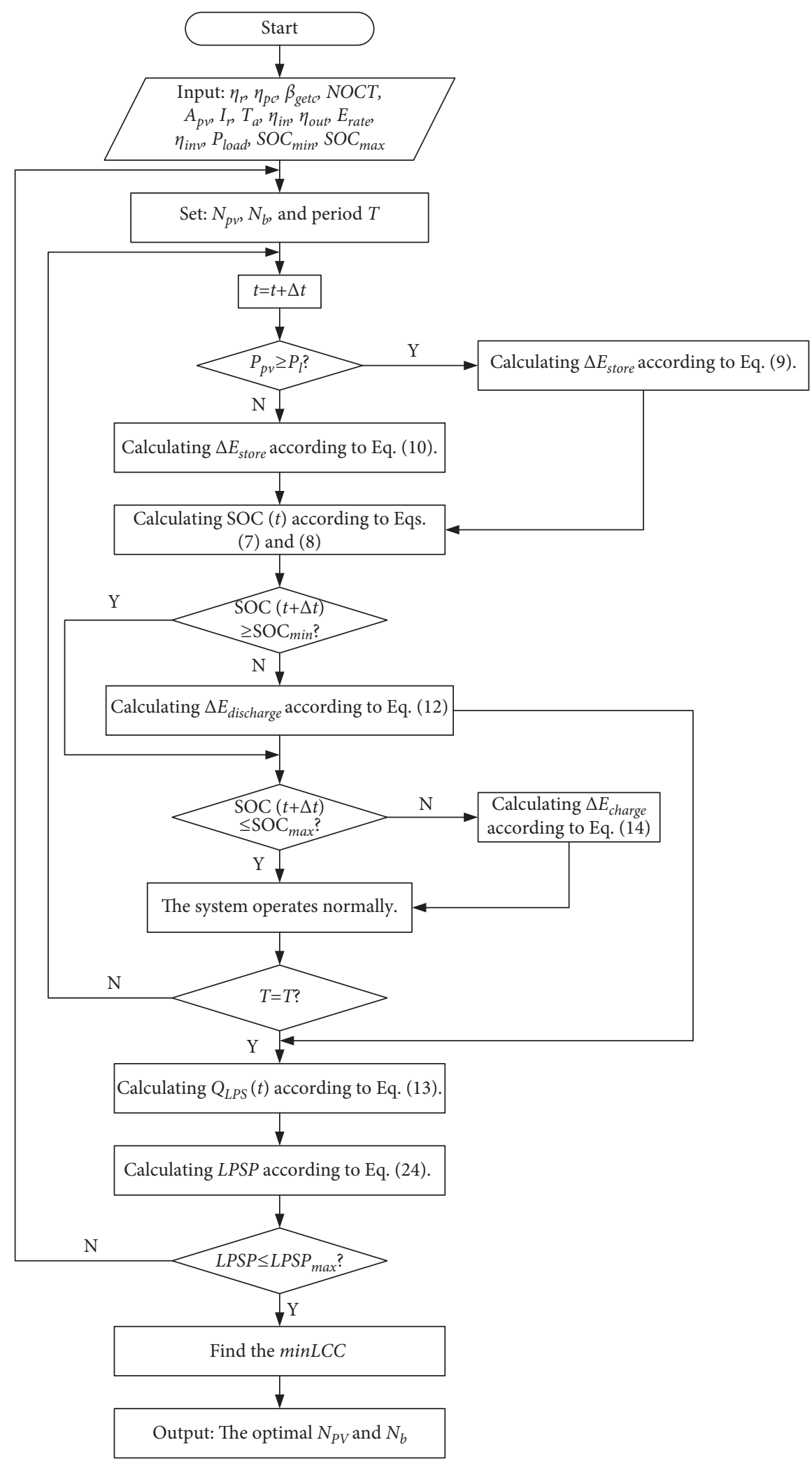

FIgURE 2: Flow chart of the optimization process and algorithm logic. 


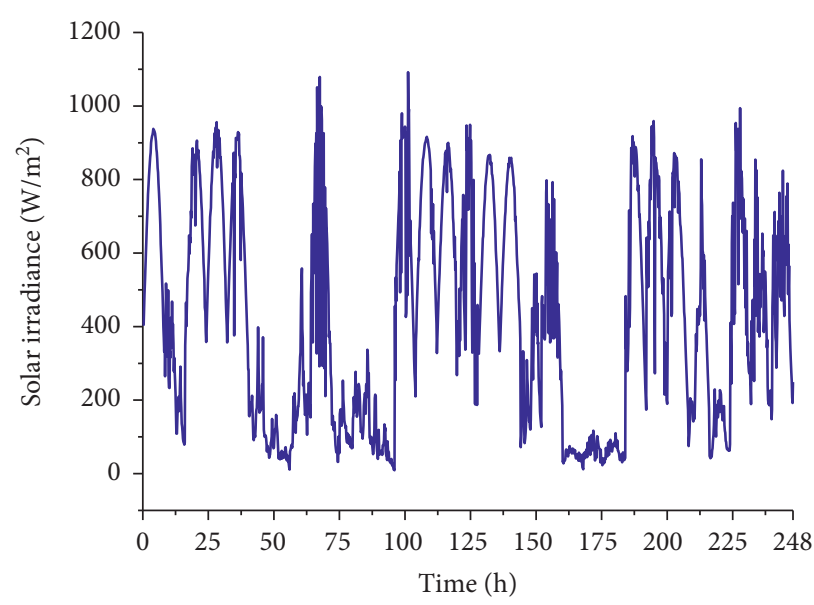

(a)



(b)

FIGURE 3: Solar irradiance and ambient temperature during the total monitoring time. (a) Solar irradiance. (b) Ambient temperature.

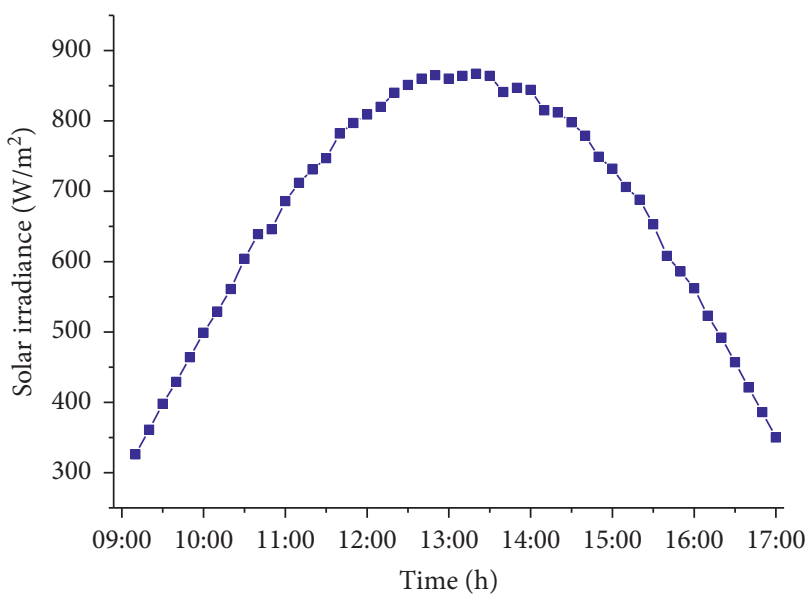

(a)

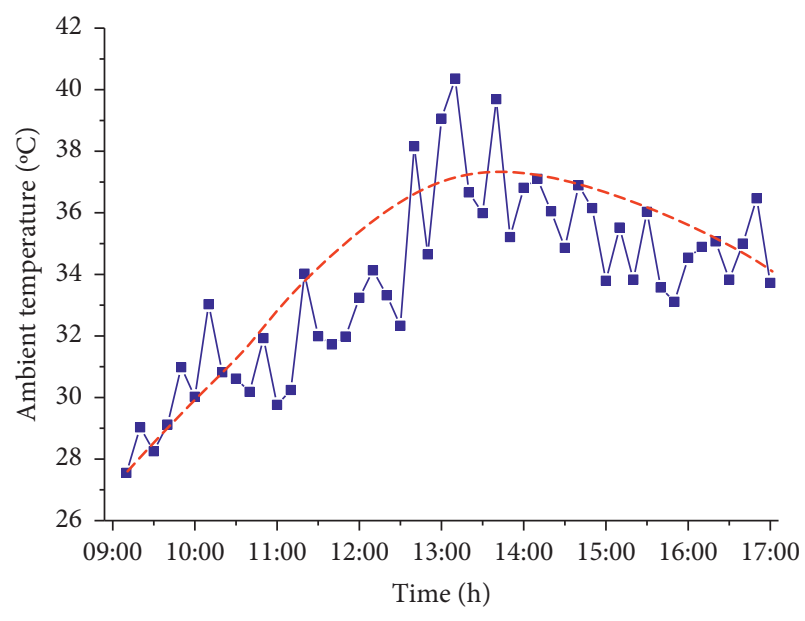

(b)

Figure 4: Solar irradiance and ambient temperature of a typical sunny day in the test area. (a) Solar irradiance. (b) Ambient temperature.

TABLE 1: The other main input parameters.

\begin{tabular}{lc}
\hline Parameters & Value \\
\hline$\eta_{\mathrm{r}}$ & 0.12 \\
$\eta_{\mathrm{pc}}$ & 0.9 \\
$\beta_{\text {getc }}$ & 0.0045 \\
NOCT & 45 \\
$A_{\mathrm{pv}}\left(\mathrm{m}^{2}\right)$ & 1.5 \\
$\eta_{\text {in }}$ & 0.9 \\
$\eta_{\text {out }}$ & 0.85 \\
$E_{\text {rate }}(\mathrm{A} \cdot \mathrm{h})$ & 200 \\
$\eta_{\text {inv }}$ & 0.95 \\
\hline
\end{tabular}

existing method reported in [7]. In [7], the technical and economic feasibility of photovoltaic pumping of water is studied. However, the loss of power supply probability (LPSP) is not considered in [7].

According to Table 2, the optimal combination of PV module and battery determined by the proposed method corresponds to No. 15 with $N_{\mathrm{pv}}=16$ and $N_{\mathrm{b}}=2$, and the minimum LCC is 28641.32 RMB. Besides, the sprinkler irrigation machine can operate continuously without loss of power supply. If the loss of power supply probability (LPSP) is not considered, the optimal combination of PV module and battery obtained using the method presented in [7] may correspond to No. 1 with $N_{\mathrm{pv}}=3$ and $N_{\mathrm{b}}=4$, and the minimum LCC is $14245.41 \mathrm{RMB}$. Although the LCC obtained using the method presented in [7] is relatively smaller, the corresponding LPSP is as high as $76.47 \%$. Consequently, the machine cannot work continuously, and the effective working time is very short.

4.3. Operation Test of Sprinkler Irrigation Machine. To verify the optimal sizing results, the solar irradiance and ambient temperature on June 5, 2018 (typical sunny day) are observed, as shown in Figure 7. Meanwhile, the sprinkler irrigation operation is also carried out using the developed sprinkler irrigation machine in the test area. 


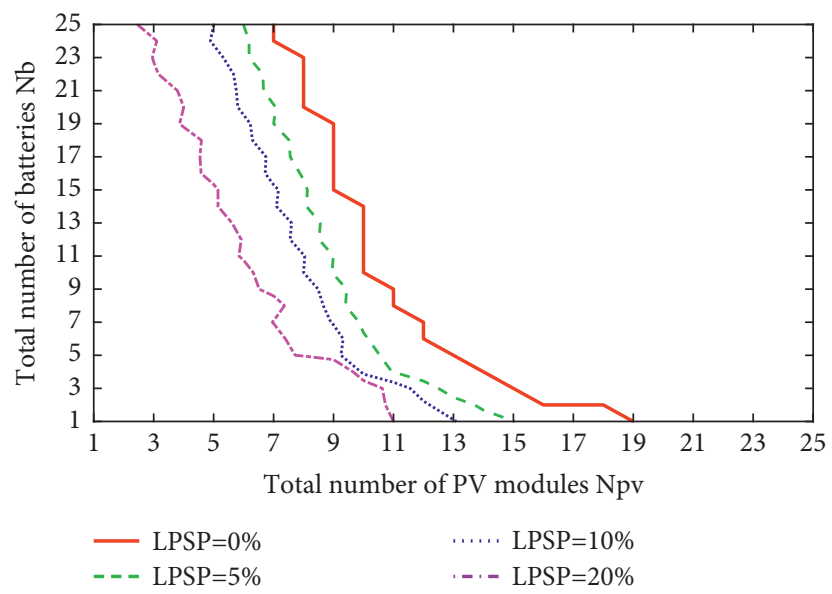

FIGURE 5: Relationship among the number of photovoltaic modules, the number of batteries, and the LPSPs.

TABLE 2: LCC comparison for different combinations of photovoltaic module and battery.

\begin{tabular}{lcccc}
\hline No. & Life cycle cost (LCC) & Loss of power supply probability $(L P S P)$ & Number of PV modules $\left(N_{\text {pv }}\right)(\%)$ & Number of batteries $\left(N_{\mathrm{b}}\right)$ \\
\hline 1 & 14245.41 & 76.47 & 3 & 4 \\
2 & 17763.98 & 70.68 & 4 & 5 \\
3 & 21282.55 & 31.84 & 5 & 6 \\
4 & 24801.12 & 24.43 & 6 & 7 \\
5 & 28319.69 & 22.46 & 7 & 8 \\
6 & 31838.26 & 12.65 & 8 & 10 \\
7 & 35356.83 & 4.74 & 9 & 11 \\
8 & 38875.40 & 0 & 10 & 12 \\
9 & 42393.97 & 0 & 11 & 12 \\
10 & 45912.54 & 0 & 13 & 13 \\
11 & 49431.11 & 0 & 14 & 13 \\
12 & 52949.68 & 0 & 15 & 16 \\
13 & 56468.25 & 0 & 16 & 16 \\
14 & 59986.82 & 0 & 16 & 2 \\
15 & 28641.32 & 0 & & \\
\hline
\end{tabular}

It can be seen from Figure 7 that the overall change trend of solar irradiance and ambient temperature on the test day is consistent with that on the typical sunny day described in Figure 4. The solar irradiance increases first and then decreases and reaches the maximum between 13:00 and 14:00. The ambient temperature rises first and then decreases slightly.

After substituting the optimal combination of $\mathrm{PV}$ module and battery $\left(N_{\mathrm{pv}}=16\right.$ and $\left.N_{\mathrm{b}}=2\right)$ into the PV system model and battery storage model, the PV power, state of charge (SOC), and load power at each time can be obtained, as shown in Figure 8. Note that the factors affecting the operation of sprinkler irrigation machines are complicated. The load power at each time is assumed to be equal to the full load power in the calculation process to ensure the normal operation of the sprinkler irrigation machine.

As shown in Figure 8, the PV power is greater than the load power at most time points. In Figure 8, between 9:00 and 10:00, the PV power is less than the load power due to the low irradiance and ambient temperature. Consequently, the battery needs to be discharged to meet the load demand. Accordingly, the state of charge (SOC) of the battery also shows a downward trend. From 10:00 to 16:30, the PV power is greater than the load power, which can meet the demand of the load. During this time period, the SOC curve fluctuates with time. The SOC value rises because the PV power is greater than the load power, and the SOC is calculated according to equation (7). The decrease of SOC value is because SOC is greater than $S O C_{\max }$, and SOC is calculated according to equation (14). From 16:30 to 17:00, the solar irradiance and ambient temperature decrease, which makes the PV power lower than the load power, and then the SOC also shows a downward trend.

In order to further verify the practicability of the selfdeveloped translational sprinkler irrigation machine and the feasibility of the optimal sizing result, the sprinkler irrigation experiment using the developed sprinkler irrigation machine was carried out in the experimental site, as shown in Figure 9.

The developed sprinkler irrigation machine, which installed 16 photovoltaic modules and two batteries, runs from 9:00 to 17:00 for a total of 8 hours, and the maximum running speed is $0.028 \mathrm{~m} / \mathrm{s}$. During operation, the flow of the pumping unit is $12 \mathrm{~m}^{3} / \mathrm{h}$, and the water-lift of the selfpriming pump of the translational sprinkler irrigation machine is $10 \mathrm{~m}$. Within 8 hours of operation, the sprinkler 




Figure 6: Relationship between LPSP and LCC.



(a)

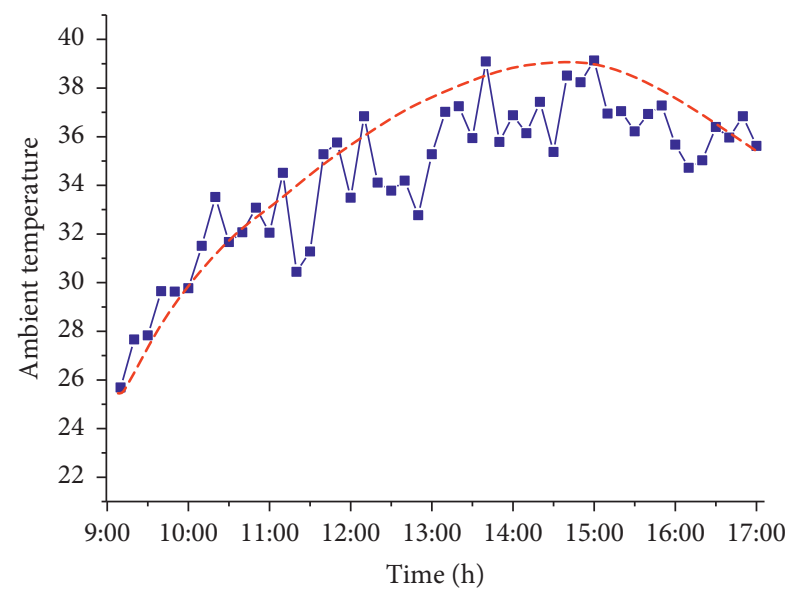

(b)

Figure 7: Solar irradiance and ambient temperature of the test day. (a) Solar irradiance. (b) Ambient temperature.

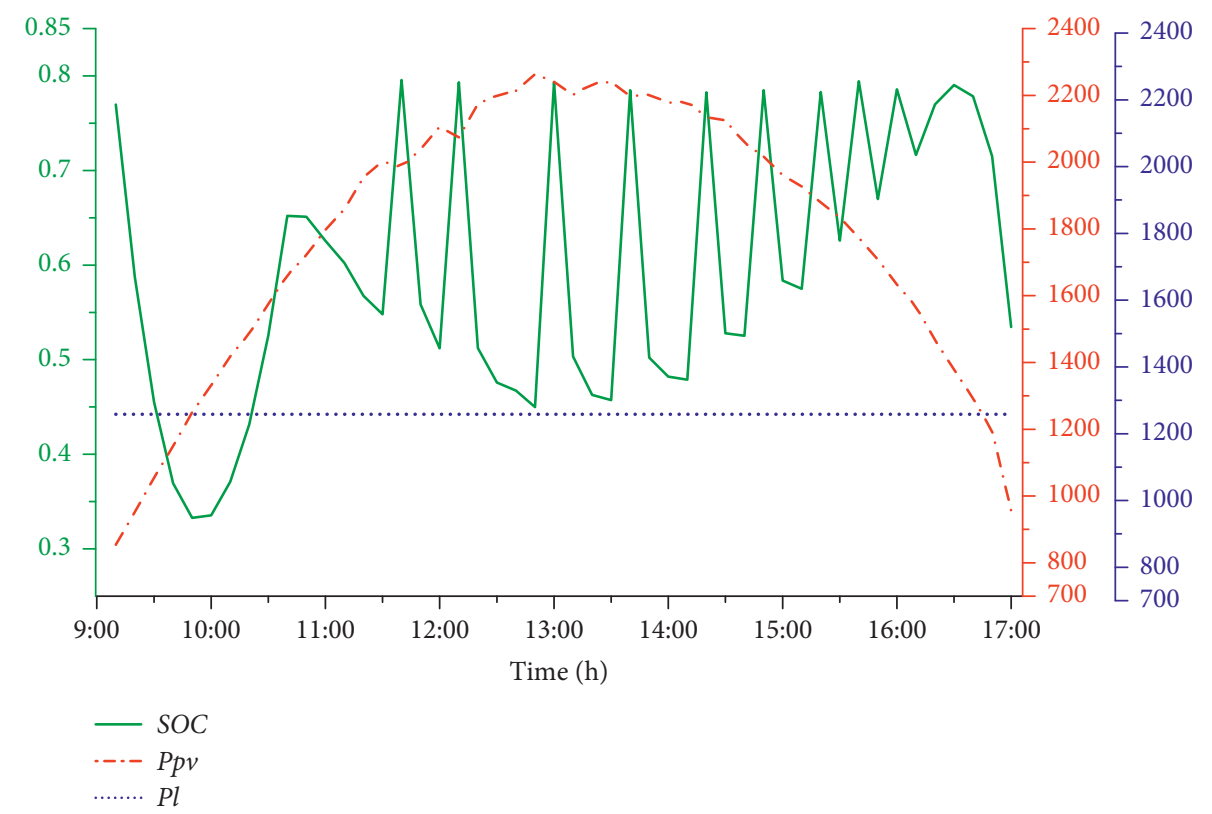

FIGURE 8: The PV power, state of charge (SOC), and load power at different time points. 


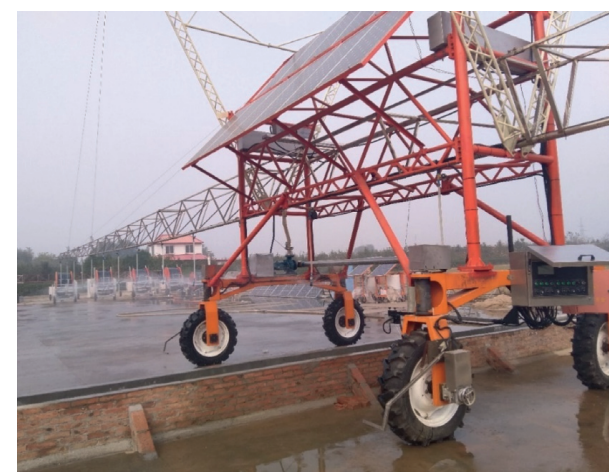

FIGURE 9: Sprinkler irrigation experiment site using the developed sprinkler irrigation machine.

irrigation machine operated continuously without loss of power supply, which further verified the effectiveness of the optimal sizing results.

\section{Conclusions}

This paper aims to optimize the stand-alone photovoltaic system for a solar-powered translational sprinkler irrigation machine. The following conclusions can be drawn:

(1) The load power, which includes the driving power of the translational sprinkler irrigation machine, water intake pressure driving power, and the loss power of the controller and sensors, is considered in the calculation process. Meanwhile, the photovoltaic generator model and the battery storage model are established.

(2) The stand-alone photovoltaic system is optimized considering the loss of power supply probability (LPSP) and the life cycle cost (LCC). The combination of PV module and battery with $N_{\mathrm{pv}}=16$ and $N_{\mathrm{b}}=2$ is proved the optimal one.

(3) By analyzing the PV power, state of charge (SOC), and load power of a typical sunny day, the optimal sizing result is proven effective and applicable. Besides, the optimal sizing result is also verified by the operation test of the sprinkler irrigation machine.

\section{Data Availability}

The data used to support the findings of this study are included within the article.

\section{Conflicts of Interest}

The authors declare no conflicts of interest.

\section{Acknowledgments}

This research was funded by the Youth Science and Technology Fund Project of Gansu Province (20JR10RA555, 20JR10RA557), the FuXi Talent Program of Gansu Agricultural University (GAUfx-04Y02), the National Natural Science Foundation of China (61661003, 61862002, 51765004,
52165028, and 52065005), the Teaching Team Project of Electrical Specialty of Gansu Agricultural University (GAUJXTD-201904), the New Engineering Research and Practice Project of Gansu Agricultural University (GAU-XGKYJSJ202007), and the Discipline Construction Fund of Gansu Agricultural University (GAU-XKJS-2018-190).

\section{References}

[1] A. Hilliard and G. A. Jamieson, "Ecological interface design for solar car strategy: from state equations to visual relations," in Proceedings of the IEEE International Conference on Systems, Man and Cybernetics, pp. 139-144, IEEE, Montreal, QC, Canada, Oct. 2007.

[2] M. E. Gamez, E. N. Sanchez, and L. J. Ricalde, "Optimal operation via a recurrent neural network of a wind-solar energy system," in Proceedings of the 2012 IEEE World Automation Congress (WAC), pp. 1-6, IEEE, San Jose, CA, USA, Aug. 2011.

[3] J. Wang, X. Zhang, and D. Kang, "Parameters design and speed control of a solar race car with in-wheel motor," in Proceedings of the 2014 IEEE Transportation Electrification Conference and Expo (ITEC), pp. 1-6, IEEE, Dearborn, MI, USA, June 2014.

[4] N. D. Nordin and H. Abdul Rahman, "A novel optimization method for designing stand alone photovoltaic system," Renewable Energy, vol. 89, pp. 706-715, 2016.

[5] N. I. Abdul Aziz, S. I. Sulaiman, S. Shaari, I. Musirin, and K. Sopian, "Optimal sizing of stand-alone photovoltaic system by minimizing the loss of power supply probability," Solar Energy, vol. 150, pp. 220-228, 2017.

[6] S. Fezai and J. Belhadj, "Sizing optimization of a stand-alone photovoltaic system using genetic algorithm," in Proceedings of the 18th international conference on Sciences and Techniques of Automatic control \& computer engineering (STA 2017), pp. 499-504, IEEE, Monastir, Tunisia, December 2017.

[7] R. Senol, "An analysis of solar energy and irrigation systems in Turkey,” Energy Policy, vol. 47, pp. 478-486, 2012.

[8] S. Sallem, M. Chaabene, and M. B. A. Kamoun, Optimum Energy Management of a Photovoltaic Water Pumping SystemSustainability in Energy and Buildings, R. J. Howlett, L. C. Jain, and S. H. Lee, Eds., Springer, Berlin, Heidelberg, pp. 187-197, 2009.

[9] S. Sallem, M. Chaabene, and M. B. A. Kamoun, "Energy management algorithm for an optimum control of a photovoltaic water pumping system," Applied Energy, vol. 86, no. 12, pp. 2671-2680, 2009.

[10] D. Abbes, A. Martinez, and G. Champenois, "Life cycle cost, embodied energy and loss of power supply probability for the optimal design of hybrid power systems," Mathematics and Computers in Simulation, vol. 98, pp. 46-62, 2013.

[11] K. Bataineh and D. Dalalah, "Optimal configuration for design of stand-alone PV system," Smart Grid and Renewable Energy, vol. 03, no. 02, pp. 139-147, 2012.

[12] E. Koutroulis, D. Kolokotsa, A. Potirakis, and K. Kalaitzakis, "Methodology for optimal sizing of stand-alone photovoltaic/ wind-generator systems using genetic algorithms," Solar Energy, vol. 80, no. 9, pp. 1072-1088, 2006.

[13] C. O. Okoye and O. Solyalı, "Optimal sizing of stand-alone photovoltaic systems in residential buildings," Energy, vol. 126, pp. 573-584, 2017.

[14] K. Liu, W. Zhao, B. Sun, P. Wu, and D. Zhu, "Application of ushak filter in the navigation of a translational sprinkler irrigation machine," Water, vol. 11, no. 6, p. 1269, 2019. 